TITLE:

PHYCOLOGICAL OBSERVATIONS VII. ON THE OCCURRENCE AND PHYCO-GEOGRAPHICAL DISTRIBUTION OF SARGASSUM DUPLICATUM AND HALICORYNE WRIGHTII IN THE PHILIPPINES

$\operatorname{AUTHOR}(\mathrm{S})$ :

Cordero, Paciente A.

CITATION:

Cordero, Paciente A.. PHYCOLOGICAL OBSERVATIONS VII. ON THE OCCURRENCE AND PHYCO-GEOGRAPHICAL DISTRIBUTION OF SARGASSUM DUPLICATUM AND HALICORYNE WRIGHTII IN THE PHILIPPINES. PUBLICATIONS OF THE SETO MARINE BIOLOGICAL LABORATORY 1980, 25(1-4): 27-38

ISSUE DATE:

1980-02-29

URL:

http://hdl.handle.net/2433/175995

RIGHT: 


\title{
PHYGOLOGIGAL OBSERVATIONS VII. ON THE OGGURRENGE AND PHYCO-GEOGRAPHICAL DISTRIBUTION OF SARGASSUM DUPLICATUM AND HALICORYNE WRIGHTII IN THE PHILIPPINES
}

\author{
Paciente A. CORDERO, Jr.
}

Division of Botany, Philippine National Herbarium, Philippine National Museum, Manila

With Text-figures 1-4 and Table 1

\begin{abstract}
The phyco-geographical distribution, based on the scheme designed by Cordero (1977), in the Philippine Archipelago of the two tropical marine algae, Halicoryne zerightii Harvey (Dasycladaceae, Chlorophyta) and Sargassum duplicatum J. Agardh (Sargassaceae, Phaeophyta), are presented. Observations show that $H$. wrightii flourishes well in the Inland Waters, while $S$. duplicatum grows favorably along the exposed coasts of the South China Sea and the Pacific Ocean. Also, records reveal that the northern-most occurrence of $H$. wrightii is in Ryukyu Islands, Japan, the southern-most in Bali, Indonesia, the westernmost on west coast of the Philippines, and the eastern-most on the Pacific coast of Japan; while in $S$. duplicatum, the northern-most occurrence is on the Pacific coast of central Japan, the southern-most in Australia, the western-most in Vietnam, and the eastern-most in Guam. Additional notes on the taxonomic descriptions of Philippine materials of $H$. wrightii and $S$. duplicatum are also included.
\end{abstract}

The presence of the genera Sargassum (Phacophyta) and Halicoryne (Chlorophyta) in tropical waters like the Philippines is well taken. In fact the two algal genera are among the more common ones reported from the Pacific Coast, South China Sea Coast, and Inland Waters of the Philippines. Biomass-wise, however, genus Sargassum is several times larger than Halicoryne.

The present study attempts to plot the specific areas of the Philippines where Sargassum duplicatum and Halicoryne wrightii are found. The reason for the choice of S. duplicatum to represent the genus Sargassum is its less complex morphological features, i.e. turbinarioid leaves among others, distinct from the rest of the species found in the Archipelago. While $H$. wrightii is selected being the only species under genus Halicoryne found in Philippine Waters.

What could be considered the earliest mention on the occurrence of $S$. duplicatum in the Philippines were found in the works of Montagne (1844) and Martens (1866), based on the collections of $\mathrm{H}$. Cumings and the Prussian Expedition to the East Asia, respectively. These reports used the binomial $S$. cristaefolium, synonym of $S$. duplicatum.

It took more than a century before another report of $S$. duplicatum in the Philippines was made separately by Menez (1961) and Domantay (1961) based on materials from

Publ. Seto Mar. Biol. Lab., XXV (1/4), 27-38, 1980.

(Article 3) 
Pangasinan. Five years later, Taylor (1966) reported some $S$. duplicatum collected by G. T. Velasquez from Puerto Galera, Oriental Mindoro. This was followed with a report by Trono (1973) using his own Sulu materials. The latest mention of this brown alga was made by Cordero (1976) using the 1965 collection of G. T. Velasquez, A. Timbol, and P. A. Cordero, Jr. from Batanes. This alga was encountered sixteen times before, but was only reported five times as shown below.

On the other hand, H. wrightii was initially reported from Mactan Island, Cebu under an incorrect name Polyphysa spicata mentioned by Dickie (1876). After over sixty years came the next mention of this green alga based on materials collected from several parts of the Archipelago (Gilbert, 1943). In 1961 this dasycladaceous alga, collected from Pangasinan, was cited by two different authors, E. Menez and J. Domantay. Then, Reyes (1972) found this alga from Siquijor Sub-Province. The latest report on the presence of $H$. wrightii was made by Cordero (1973) using his own collections from Biliran Sub-Province. The other ten encounters of the alga in various areas of the country have remained unreported.

\section{Distributional Survey in the Philippine Waters}

Our data on their occurrence and distributions in the Philippines waters (Fig. 1) are based from available literature, personal observations in the field, as well as from studies of herbarium specimens (Tab. 1). These data and other information on the marine algae of the Philippines motivated the author to report on their phyco-geographical distributions based on the scheme designed by Cordero (1977). Thus Region I or North-western Luzon Coastal Region, approximately $21^{\circ}$ to $12^{\circ} 5^{\prime} \mathrm{N}$ latitude and $117^{\circ}$ to $122-124^{\circ} \mathrm{E}$ longitude; Region II or South-western or MindanaoSulu-Palawan, approximately $4^{\circ} 2^{\prime}$ to $12^{\circ} 5^{\prime} \mathrm{N}$ latitude and $117^{\circ}$ to $121-122^{\circ} \mathrm{E}$ longitude; Region III or North-eastern Luzon Coastal Region, approximately $12^{\circ} 5^{\prime}$ to $21^{\circ} \mathrm{N}$ latitude and $122^{\circ}$ to $126^{\circ} 5^{\prime} \mathrm{W}$ longitude; Region IV or South-eastern or VisayasMindanao Coastal Region, approximately $4^{\circ} 2^{\prime}$ to $12^{\circ} 5^{\prime} \mathrm{N}$ latitude and $121^{\circ}$ to $127^{\circ} \mathrm{W}$ longitude; and Region V or Inland Waters include the islands whose coasts are not directly exposed to either the South China Sea or Pacific Ocean, in contrast to Regions I and II facing the South China Sea and Regions III and IV facing the Pacific Ocean.

Sargassum duplicatum observed in the five phycogeographical regions were found to have similar habitat, subtratum, algal species sociation, and growing habit. The habitat is always marine with no trace in areas where freshwater oozes into the sea. This proves its tolerance to high salinity of water. The alga prefers rocky substratum which affords it a stronger and steadier anchorage. Their massive scutate holdfast and sturdy gross morphological structures appear like adaptations for the alga to thrive in the upper intertidal portion of the shore. This particular portion of the shore is normally rough brought about by constant water movement and endless beating of waves during stormy days. They are most luxuriant under such prevailing ecological conditions and reach 'maximum' growth in summer as evidenced by some specimens from Dumatad, Tangalan, Aklan averaging $35.5 \mathrm{~cm}$ in height. Also, it is in summer 
Table 1. Records of $H$. wrightii and $S$. duplicatum in the Philippines.

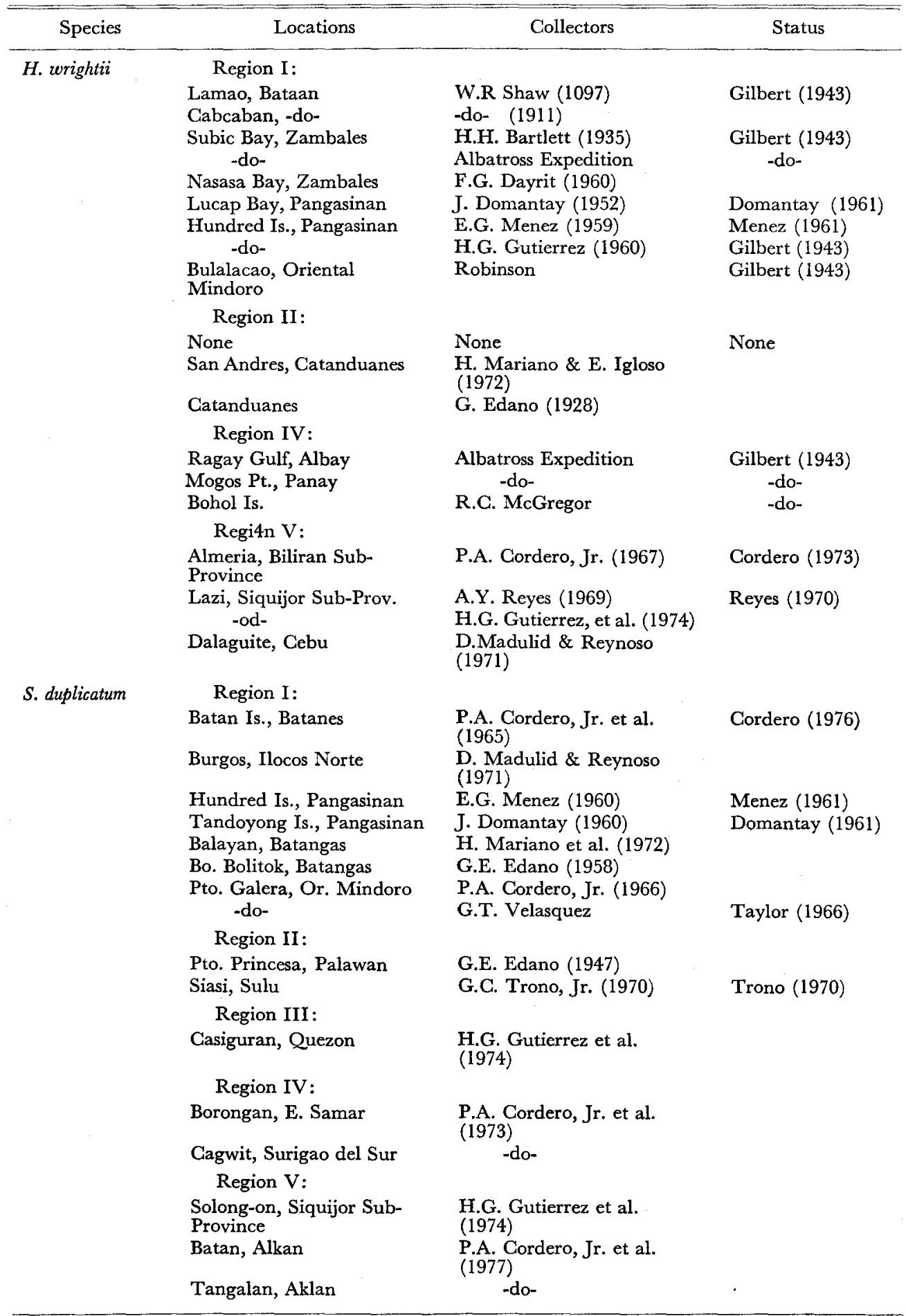




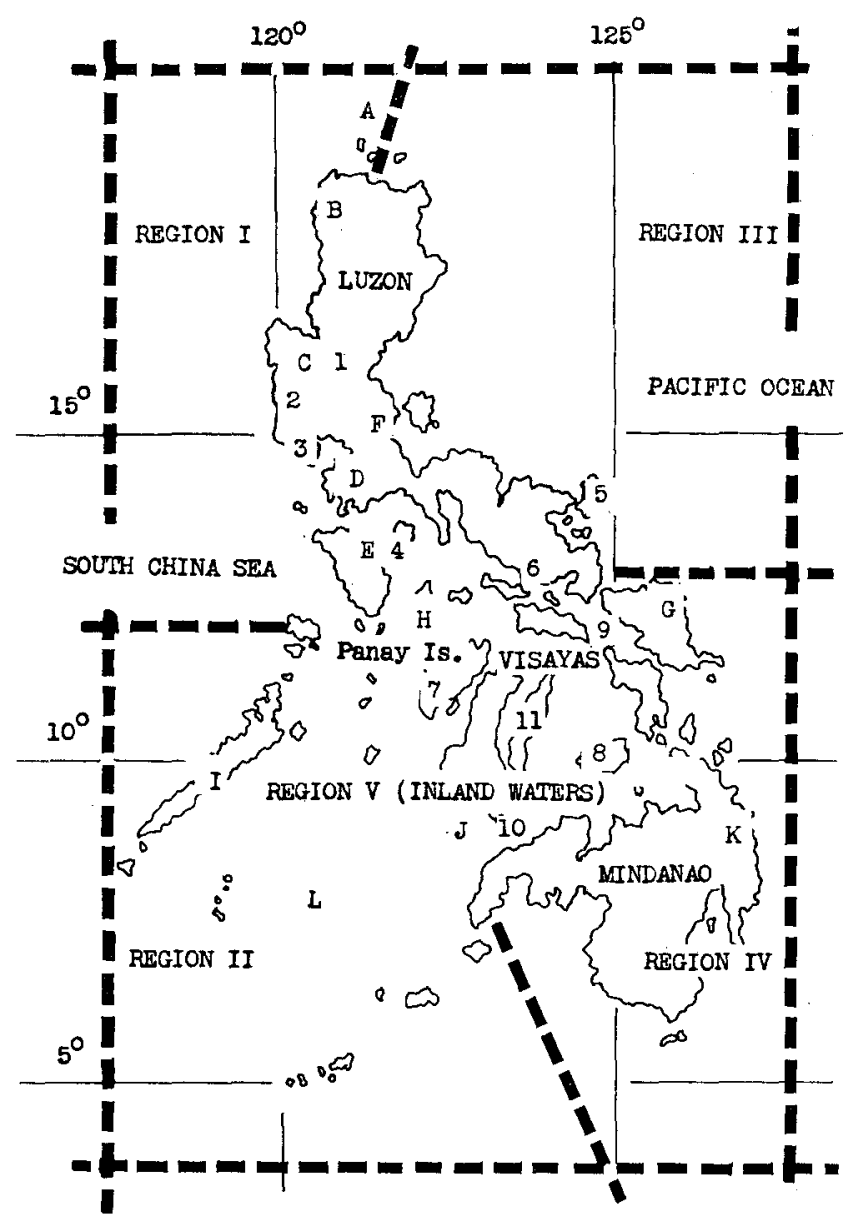

Fig. 1. Philippine Archipelago, showing five phycogeographical regions and different collecting points (alphabets, for $S$. duplicatum; figures, for $H$. wrightii).

when $S$. duplicatum shows fully developed pneumatocysts or air vesicles as well as reproductive organs. During the rainy season this brown alga are generally dwarf and juvenile as shown by complete specimens studied from Surigao del Sur and Batangas with heights ranging from $7.5 \mathrm{~cm}$ to $8.5 \mathrm{~cm}$, respectively. Further observations show that there is not much tangible growth variations between $S$. duplicatum growing in the South China Sea from those in the Pacific Coast, suggesting further that there physico-chemical preferences such as salinity, $\mathrm{pH}$, water temperature, and photicity of water are negligible. From both flanks of the Archipelago, observations show the tendency of $S$. duplicatum to grow in patches to colonial, but rarely solitary. Most often than not the algal species growing together with $S$. duplicatum are mostly brown ones like Turbinaria, Hormophysa, other Sargassum species, and few low-growing red algae, i.e. coralline forms.

A similar case happens with $H$. wrightii except for the types of habitat and kinds of algal species growing in association. This green alga, brought about by its frail and 
fragile thallus, are unable to exist in turbulent areas like the upper intertidal zone. In contrary this alga is found in protected coves and inlets growing in thick colonies.

The algal species usually found growing with $H$. wrightii are green ones such as the other dasycladaceous algae Neomeris, Bornetella, and Acetabularia which is occasionally mixed with Chondrococcus, a red algal species.

From Region I impressive collection of $H$. wrightii were made from four provinces which were ably reported viz. Bataan, Zambales, and Oriental Mindoro (Gilbert, 1943), and Pangasinan (Menez, 1961; Domantay, 1961). While S. duplicatum is positive in five provinces, but only specimens from Pangasinan (Menez, 1961; Domantay, 1961), Oriental Mindoro (Taylor, 1966), and Batanes (Cordero, 1976), were reported.

The apparent 'absence' of $H$. wrightii in Region II presents a puzzle to the writer. This is in mark contrast with $S$. duplicatum whose presence in Palawan particularly is evidenced by the 1947 collections of G. E. Edano presently deposited in the Philippine National Herbarium.

Our record on the occurrence of $H$. wrightii in Region IV is based on the observations made by Ms. Brillia Tiu, master of science student, Graduate School, University of Santo Tomas. She found this alga growing in patches in Dinagat Island at the upper tip of Surigao del Norte. An earlier investigation conducted by this author in 1976 at Cagwait, Surigao del Sur failed to trace the presence of this green alga. Instead, beds of $S$. duplicatum were found in the afore-said collecting area.

In Region V H. wrightii is well reported especially from Biliran Sub-Province (Cordero, 1973; Sis. H. Puig, pers. com.), Siquijor (Reyes, 1972), Gebu (Dickie, 1876 as Polyphysa spicata), Albay, Panay, and Bohol (Gilbert, 1943). While S. duplicatum, though collected from several areas in Region $\mathrm{V}$, has remained mostly unreported.

Few collections of $H$. zerightii and $S$. duplicatum from Catanduanes and Quezon, respectively, kept in the Philippine National Herbarium previously unreported, are included in this paper.

\section{Phyto-geographical Distribution}

A) Philippines. At present, based on the distributional data obtained and personal observations undertaken, it appears that both $H$. wrightii and $S$. duplicatum seem to be common constituents of the algal flora of the South China Sea Coast or west flank of the Philippines. So far, from the west flank of the country, there are four provinces where $H$. wrightii have been positively reported, while $S$. duplicatum has been collected from seven provinces. There are fewer records for both algae from the Pacific Coast or east flank of the country, with only two and three provinces authentically reporting $H$. wrightii and $S$. duplicalum, respectively. However, H. wrightii seems to "flourish" in the Inland Waters evidenced by its presence in the six provinces not directly washed neither by the South China Sea nor the Pacific Ocean.

The local occurrence but uneven distribution of $H$. wrightii in both flanks of the Philippines save in the Inland Waters should be attributed to a combination of several 
ecological factors. These are rocky substratum, moderate water movement and medium to high salinity. The presence of only one of these factors may attribute to the absence of the alga in a particular area. The spores of $H$. wrightii need hard, rough and more or less permanent substrates, i.e. submerged rocks or logs upon which to settle and germinate. Our observations show its preference to grow on the rough surface of submerged rocks. It is, therefore, normal not to find any trace of the alga in situations where the substrate is composed of smooth-surfaced loose rocks and/or sandy materials. Another factor, water movement, is understood here to be the water situation prevailing in the upper intertidal zone. Simply attributed to its frail gross morphological set-up $H$. wrightii and similarly built algae are nowhere to be found in areas facing the open seas where the water turbulently and continuously move. This explains why $H$. worightii are found in the lower portion of the intertidal zone, especially so in more protected areas. The third factor, salinity, plays an important role in the dispersal and proliferation of marine algae. Certainly, $H$. wrightii counts among the least resistant alga to salinity changes-being a truly marine algal form. So that, this alga is totally absent near mouths of rivers, streams, and lakes. The availability, therefore, of the afore-said three ecological factors presents a strong probability that $H$. wrightii thrives in such an area. This, however, is not to disregard other contributory factors necessary to the growth of this green alga. It is natural then for $H$. wrightii to proliferate in the Inland Waters of the Philippines where the three factors combine most of the time. This is especially true in Almeria, Biliran sub-Province, Leyte which was visited twice in 1967 and 1972.

On the other hand, S. duplicatum, which needs for its growth similar factors stated above, is more resistant to excessive water movement. Its sturdy gross-morphological set-up is indeed an adaptation to live in the wave-beaten upper portion of the intertidal zone. This situation is common in the exposed or unprotected coasts of the Archipelago facing the South China Sea and Pacific Ocean. Such kind of a habitat permits growth to only the more wave resistant algae such as the brown species of Turbinaria, Hormophysa and Sargassum. It cannot be concretely explained though, why there are fewer reports of $S$. duplicatum from the Pacific Coast compared with those from the South China Sea Coast of the Country?

Additionally, $S$. duplicatum is absent in areas where freshwater empties into the sea suggesting that its resistance to low salinity is zero.

B) Adjacent Regions. Our records at hand show that both $H$. wrightii and $S$. duplicatum are modestly distributed in regions adjacent to the Philippines. For $H$. wrightii our northern-most distributional record is Ryukyu or Liu-kiu Islands, Japan (Okamura, 1908) and southern-most is Bali, Indonesia based on two dried specimens deposited in the Philippine National Herbarium. These 1929-1930 collections of W. A. and G. B. Setchell, identified by W. R. Taylor, were sent to the Philippines as exchange materials from the University of California Herbarium. Thus, its southerly to northerly distribution is approximately from $0^{\circ}$ (Bali, Indonesia) to $35^{\circ}$ (Ryukyu Islands, Japan), while its easterly to westerly limits is approximately from $120^{\circ}$ (West coast of the Philippines) to $140^{\circ}$ (Pacific side of Southern Japan) W. lontigude, rather 


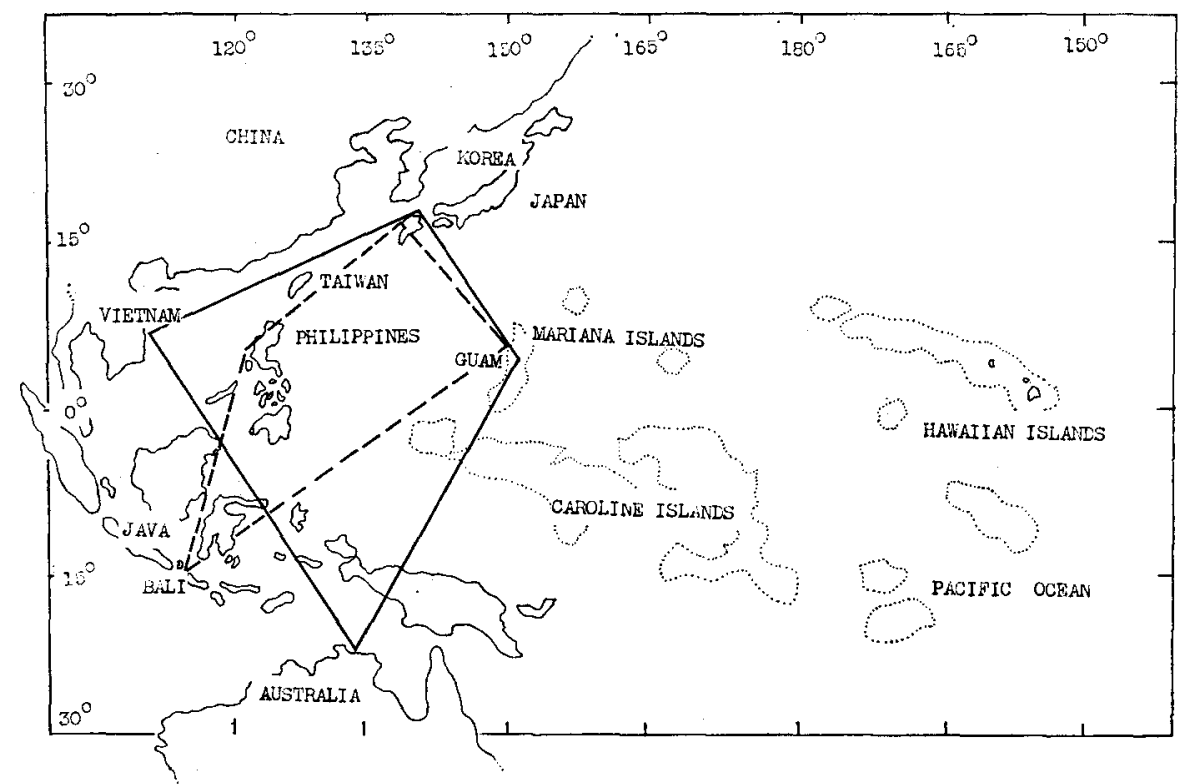

Fig. 2. Geographical distribution of $S$. duplicatum (in straight lines) and H. wrightii (in borken lines).

generally confined to the tropical regions of the Pacific Ocean and South China Sea. However, the apparent absence of $H$. wrightii in the South Pacific Ocean, particularly in the Micronesia Island group almost lying parallel to the Philippines seems difficult to explain. Neither are we in the best position to explain the want of reports of this alga from the tropical region of the Indian Ocean. We can only hypothetically say that the restrictive distribution of $H$. wrightii is a peculiar feature of the alga that its spores can be borne only to a limited distance by oceanic currents of high temperature.

A rather different distributional data is presented by $S$. duplicatum as evidenced by the richer reports emanating from regions adjacent to the Philippine Archipelago. Our data dictate that the southern-most limit of this brown alga is Australia (approx. $20^{\circ} \mathrm{S}$ latitude and $140^{\circ} \mathrm{E}$ long, ), northern-most is Central Pacific Japan (approx. $35^{\circ} \mathrm{N}$ lat. and $140^{\circ} \mathrm{E}$ long.), Western-most is Vietnam (approx. $20^{\circ} \mathrm{N}$ lat. and $110^{\circ} \mathrm{E}$ long.), and the Eastern-most is Guam (approx. $120^{\circ} \mathrm{N}$ lat. and $145^{\circ} \mathrm{E}$ long.). The preliminary plot on the distribution of $S$. duplicatum is based from the reports of J. Agardh from Australia; Segawa (1934) and Yamada and Tanaka (1938) from Japan: Ho (1966) from Vietnam.

These data are supplemented by reports on the occurrence of $S$. duplicatum from the Philippines such as those by Menez (1961), Domantay (1961), Taylor (1966), Trono (1973), and Cordero (1976). Substantial reports about the alga came from New Zealand and the Indian Ocean. However, its presence in the South Pacific island of Guam could have been made possibly by the current moving towards that direction bearing the spores of the alga and its subsequent growth in the area "... inhabits the inner margin on Guam (Tsuda, 1971)..." 
Furthermore, it appears that among the members of Family Dasycladaceae found in the Philippines and adjacent regions, i.e. Bornetella, Cymopolia, Dasycladus Halicoryne, and Neomeris, only Halicoryne has the most restrictive geographical distribution. Others are found in the Polynesian waters and Malaysian Archipelago. Of the five genera Neomeris is the most extensively distributed having been reported from the West Coast of America, Indian Ocean and Atlantic Ocean. By comparing the distributional limits of the four genera closely related to genus Halicoryne, it might be safe to designate the Tropical West Pacific to be its point of divergence.

On the other hand, the extent of distribution of $S$. duplicatum when compared with $S$. piluliferum and $S$. patens, is very narrow considering that the latter two Sargassum species are not only found in the warm tropical regions but also in the West Coast of America and Bering Sea, respectively. Add to this the large number of Sargassum species reported from the Pacific Ocean which outnumbers those from the Indian Ocean and Atlantic Ocean. Similarly, therefore, we could say that the point of divergence of $S$. duplicatum follows that of $H$. wrightii.

\section{Morphological Observations}

\section{Class CHLOROPHYCEAE, Family Dasycladaceae}

Halicoryne wrightii Harvey (Fig. 3)

Okamura 1908: 217, pl. 43; Yamada 1934: 59, fig. 26; Gilbert 1943: 27; Segawa 1956: 13, pl. 7, fig. 59; Cordero 1973: 19.

Plant averages $6.5 \mathrm{~cm}$ tall, clavate, erect, unbranched, and green to pale green upon drying. Its central axis, usually bare towards the base, shows two sizes brought about by the loss of whorly arranged fertile and sterile polychotomous branches. The fertile branches may reach 18 per whorl, to $2.5 \mathrm{~mm}$ long oftentimes imbricately positioned.

Among our large collections of $H$. wrightii, we found out that those gathered during the rainy season are rather dwarf, averaging $3 \mathrm{~cm}$ tall (PNH 113938 from Dalaguite, Cebu), while those gathered during the dry season average $7 \mathrm{~cm}$ tall, some reaching $11.5 \mathrm{~cm}$ in height (PNH 113987 from Zambales). This height differences could be indications that $H$. wrightii reaches maturity in summer. The plant is always colonial in habit. Our oldest material examined was collected in 1907 by W. R. Shaw from Lamao, Bataan.

According to Gilbert (1943) “... the first record of a plant of this family (Dasycladaceae) from the Philippines is that of Polyphysa spicata Kuetzing by Dickie (1876), the material having been collected at Matcan by the "Challenger" expedition." Philippine materials examined:

South China Sea-PANGASINAN: PNH 113795, Lucap Bay, Lingayen, J. Domantay, 1952; PNH 41436, Alo Island, Alaminos, H. G. Gutierrez, April 1960. ZAMBALES: PNH 40271 and PNH 113987, Nasasa Bay, F. G. Dayrit, February 


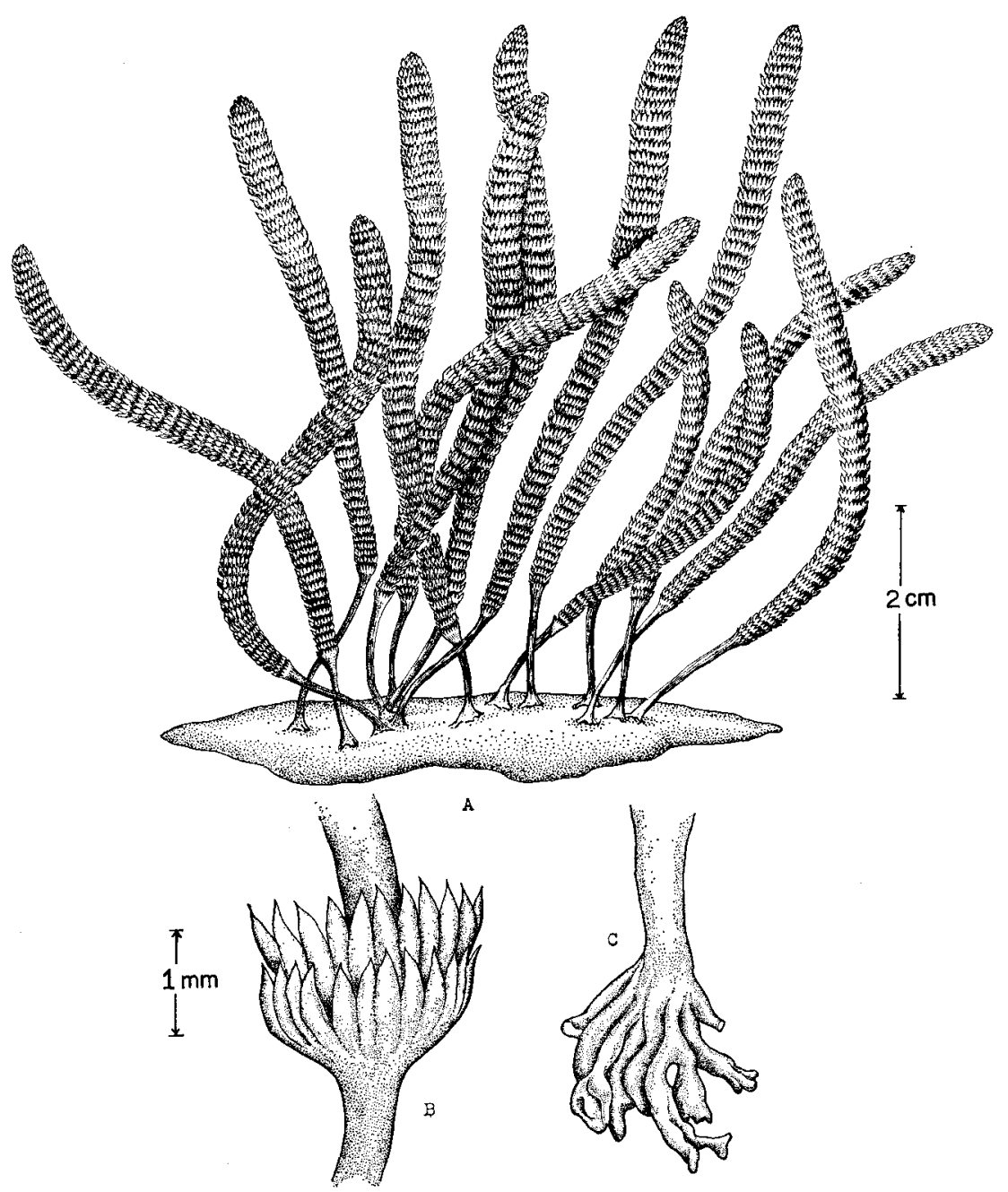

Fig. 3. Halicoryne wrightii Harvey (PNH 113987). (A) habit of the plant; (B) detailed drawing of whorly arranged branches; (C) root-system.

1960. BATAAN: (Bureau of Science number) 1131, Cabacaban, May 1911, W. R. Shaw.

Pacific Ocean-CATANDUANES: (Bureau of Science number) 77263, M. Ramos and G. E. Edano, July-September 1928; PNH 114088, San Andres, Mariano and Igloso, August 1972.

Inland Waters-BILIRAN: PNH 97660, Bo. Talahid, Almeria; PNH 97678 and PNH 97670, Lo-ok Pt., Almeria; PNH 113903, N. of Almeria Bay, Almeria, P. A. Cordero, Jr., May 1967. CEBU: PNH 113938, Casay, Dalaguite, D. Madulid and E. Reynoso, December 1971. SIQUIJOR: PNH 112032, Simacolong, Lazi, A. Y. Reyes, May 1972; PNH 114549, Lazi, H. G. Gutierrez, et al, 1974. 
Foreign materials examined:

INDONESIA: BK-10 (no PNH number), Kampoengan, Bali, Setchell \& Setchell, June 19, 1929; BK-292 (no PNH number), Bali, Oie Yong Seng, 1929-1930.

\title{
Class PHAEOPHYCEAE, Family Sargassaceae \\ Sargassum duplicatum J. Agardh (Fig. 4)
}

\author{
Weber van-Bosse 1913: 137; Okamura 1923: 10, pl. CCV; Chihara 1970: 56; Cordero 1976: 22. \\ S. ilicifolium var. duplicatum J. Agardh \\ S. cristaefolium Harvey
}

Plant saxicolous anchored by means of massive scutate disc holdfast $35 \mathrm{~cm}$ tall, terete, brownish, moderately branched with cylindrical branches. Its leaves are shortly stipitate, obovate, coriaceous with duplicated margin provided with denticulate growth issued from the intra-marginal surface. Air vesicles or pneumatocysts are few, spherical, winged about $4 \mathrm{~cm}$ in diameter, cryptostomata are seen as heavily stained dots scattered all over the leaves and air vesicles. Receptacles are held by short stalk and assume a cymose outline.

Our tallest specimen was collected from Taııalan, Aklan, reaching $35.5 \mathrm{~cm}$ tall, while the shortest is barely $7.5 \mathrm{~cm}$ from Siquijor sub-Province. Only few of the specimens examined had pneumatocysts and receptacles, especially those gathered during the rainy months.

The oldest materials examined are the 1947 collections of G. Edano, while the latest were collected in 1977 by the present writer.

Philippine materials examined:

South China Sea-BATANES: PNH 96968 (also GTV 6288a), Chanarian, Basco, P. A. Cordero, Jr. et al., May 1965; ILOCOS NORTE: PNH 113849, Bobon, Burgos, D. Madulid and E. Reynoso, March 1971. PANGASINAN: PNH 113789, Hundred Islands, J. Domantay, May 1953. BATANGAS: PNH 114066, Balayan, San Juan, Mariano et al., February 1972; PNH 40581, Bo. Bolitok, G. Edano, November 1958. PALAWAN: (Bureau of Science number) 636, 638, and 907, Puerto Princesa, G. Edano, March 1947. ORIENTAL MINDORO: PNH 96709, Baradero Bay, Puerto Galera, P. A. Cordero, Jr. et al., April 1966.

Pacific Ocean-QUEZON: PNH 115454, Dibacong, Casiguran, H. G. Gutierrez et al, November 1974. EASTERN SAMAR: PNH 112396, Punta Maria, Borongan, P. A. Cordero, Jr. et al., May 1973. SURIGAO DEL SUR: PNH 122281, N. Tawagan, Cagwait, P. A. Cordero, Jr., November 1976.

Inland Waters-AKLAN: PNH 123271, NE Batan; PNH 123336, Ob-ob, Batan; PNH 123188, Afga, Tangalan; PNH 123235, PNH 123238, PNH 123231-A, PNH 123232, Dumatad, Tangalan, P. A. Cordero, Jr. et al., April-May 1977. SIQUIJOR: PNH 114473, Bo. Solong-on, Siquijor; PNH 114570, Lazi, H. G. Gutierrez et al., March 1974. 


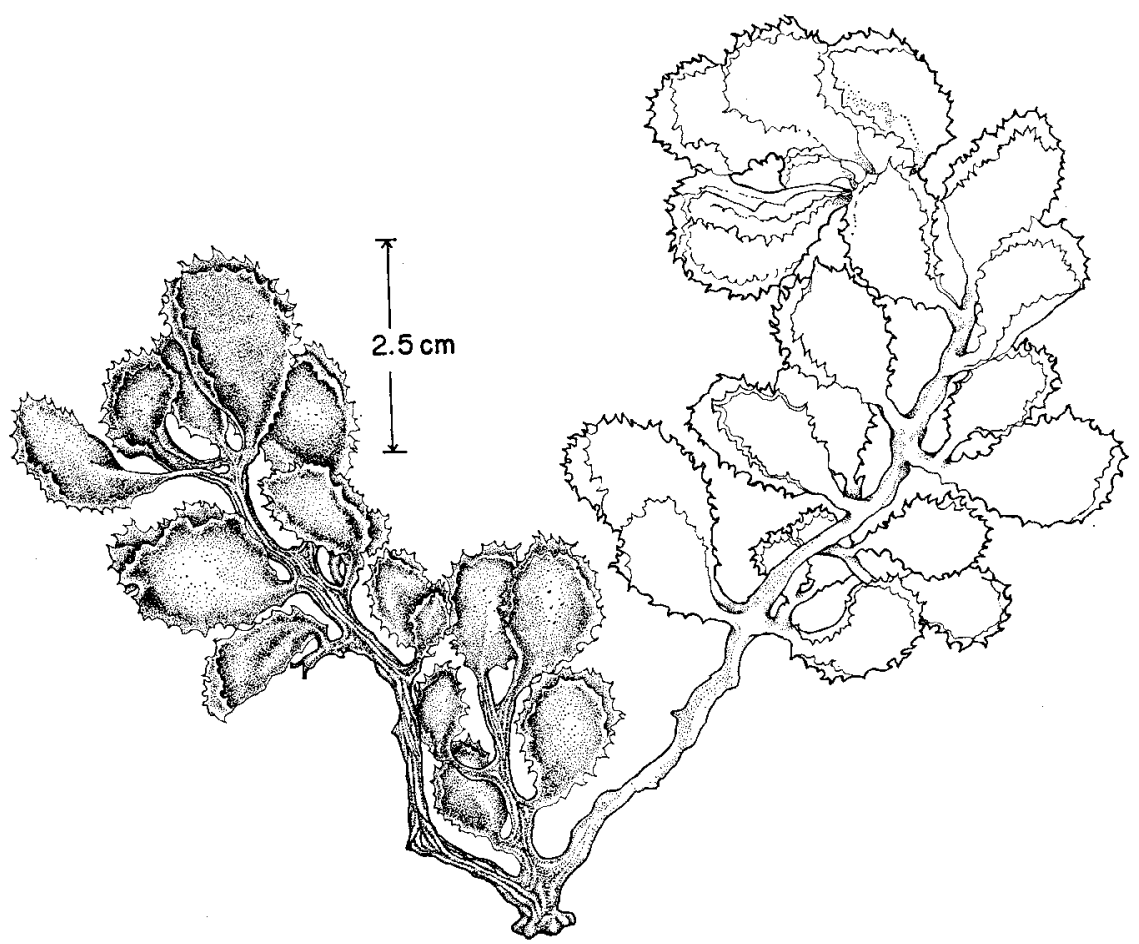

Fig. 4. Sargassum duplicatum J. Agardh (PNH 96968). Habit of the plant showing turbinarioid leaves.

Foreign materials examined:

JAPAN: PNH 113751, Nagasakibana, Kagoshima Prefecture, P. A. Cordero, Jr., 1971.

\section{Acknowledgements}

The author is indebted to his colleagues in the Philippine National Herbarium and the personal employed under the National Research Council of the Philippines Research Project GF-V-4, who helped gather numerous marine algal specimens and other field data; and, the Philippine Government thru the National Museum and National Research Council for the financial assistance extended during the course of the investigation.

\section{LITERATURE GITED}

Chihara, M. 1970. Common Seaweeds of Japan in color. 173 p. Japan.

Cordero, Jr. P.A. 1976. The Marine Algae of Batan Island, Northern Philippines. Fish. Res. Jour. Phil. 1 (2): 3-29; figs. A-O.

Dickie, G. 1876. Contribution to the Botany of the Expedition of H.M.S. "Challenger."-Algae, Chiefly Polynesian. Jour. Linn. Soc. Bot., 15: 235-246. 
Domantay, J. 1961. An Ecological Survey of the Marine Vegetation of the Hundred Islands and Vicinity Phil. Jour. Sci. 90: 271-295.

Gilbert, W.J. 1943. Studies on Philippine Chlorophyceae I. The Dasycladaceae. Pap. Mich. Acad. Sci. Arts and Letters 28: 15-35.

Ho, P.H. 1966. Liste preliminaire des algues et monocotyledones trouvees a Hon-thu. Les Exped. Sci. 1: 17-48.

Menez, E.G. 1961. The Marine Algae of the Hundred Islands, Philippines. Phil. Jour. Sci. 90: 37-87.

Okamura, K. 1908. Icones of Japanese Algae, 1 (9), 1907-37. Published by the author.

Okamura, K. 1923. Icones of Japanese Algae, 4: 1-205. Published by the author.

Reyes, A.Y. 1970. A Survey of the Littoral Benthic Algae of the Coastal Areas of Dumaguete City. Phil. Jour. Sci. 99: 131-163.

Segawa, S. 1934. On the Marine Algae of Susaki Prov. Idzu. Sci. Pap. Inst. Algol. Res., Fac. Sci., Hokkaido Imp. Univ. I(1): 59-90, pls. 19-20.

Segawa, S. 1956. Coloured Illustrations of Seaweeds of Japan. 175 p. 84 pls. Osaka.

Taylor, W.R. 1966. Records of Asian and Western Pacific Marine Algae, particularly from Indonesia and the Philippines. Pac. Sci. 20 (3): 342-359.

Trono, Jr. C.G. 1973. The Marine Benthic Algae of Siasi Island and Vicinity II. Phaeophyta. KALIKASAN, Philipp. J. Biol. 2: 140 148.

Tsuda, R. 1971. Occurrence of the genus Sargassum (Phacophyta) on Two Pacific Atolls. Micronesica $12(2): 279-282$.

Weber van-Bosse, A. 1913. Liste des algues du Siboga, I (Myxophyceae, Chlorophyceae, Phaeophyceae) Siboga Exped. 59a; 1-186, t pls. E.J. Brill. Leiden.

Yamada, Y. 1934. The Marine Chlorophyceae from Ryukyu, especially from the vicinity of Nawa. Jour. Fac. Sci. Hokkaido Imp. Univ., 3 (2) : 33-88.

Yamada, Y. and T. Tanaka 1938. The Marine Algae from the Islands Yonakuni. Sci., Hokkaido Imp. Univ. 2 (1): 53-86. 